the patients are disfigured against their will ; but they should not be thus permitted to fall into a negligence which is characteristic of advanced and incurable forms of disorder.

\title{
TUMOR OF THE ORBIT.
}

By R. L. Howard, M.D., of Oolumbus, Ohio.

Mrs. Rebecca Pope, aged 40 years, of light complexion, spare habit, and the mother of several children.

This lady was brought from Fairfield Co., O., to Columbus, about one year ago, at the time when the Ohio State Medical Convention was in session, for the purpose of consulting some of its members concerning a large and nodulated turnor which completely filled the orbit of the left eye. The history of the case is nearly as follows. At the early age of 12 years she noticed the sight of the left eye began to fail, and continued to do so until she was 17 , when the sight was entirely lost, and the eye itself so prominent that her pliysicians supposed it to be a dropsical enlargement, for which they punctured the globe. Nothing escaped of consequence, but a violent inflamınation supervened, which occasioned a collapse and atrophy of the organ. For about twenty years she experienced no particular inconvenience from it; but about two years previous to her visit to Columbus, she began to feel some uneasiness and pain, together with a decided increase of morbid growth in the socket. The symptoms becane so alarming, that she now resolved to seek relief.

At that time she was visited and examined by Drs. Mussey and Judkins, of Cincinnati, and several of the older members of the Convention, who were unanimously of the opinion that the turnor was probably malignant, and that the only chance of relief would be found in an immediate extirpation.

The tumor itself completely filled the orbit, and projected considerably beyond the brow and malar prominence. It seerned firnly fixed in its position, and quite immovable. Upon its anterior surface was imbedded the globe, flattened and diminished to one eiglth its natural size. The palpebræ were widely separated, and unable to cover the tumor.

In consultation I agreed with all the other medical gentlemen, that the entire morbid growth should be removed with the knife, and advised her to submit to an operation which would afford a fair, or, at least, the only prospect of cure-to which she with but little delay consented.

With the assistance of my friends, Drs. Schenck, Smith, Denig and Taylor, and in the presence of several medical students, $I$ proceeded, on the 24th of May, 1845, to extirpate the eye and tumor. The patient was placed in an easy chair, with her hend thrown back, and held by an assistant. The external cominissure of the lids was divided backwards; the bistoury was then passed between the tumor and the walls of the orbit, nearly to the bottom of the socket, and carried carefully around it until it arrived at the place of entrance. A little dissection with the point of the instrument removed the entire contents of the orbit. The 
hæmorrhage was not profuse, and the patient bore her sufferings with remarkable fortitude. The cavity was lightly filled with lint, suitable dressings applied, and the patient laid in bed. As the pain in the part was severe, one third of a grain of morphine was administered, which soon afforded relief, when she expressed herself as exceedingly gratified that she bad submitted to the operation.

May 25th, morning.- Rested but little during the night. Nausea and vomiting, pain in the head and general distress had all supervened to an alarming degree. Appropriate remedies were prescribed to allay the irritation of the stomach, and divert the tendency to cerebral disease, but to little purpose. During the afternoon, she exhibited symptoms of approaching delirium, and in the evening her mind was decidedly wandering. Prescribed tiventy grains of calomel in divided doses, sinapisms to the extremities, cold water to the head, and blister to the nape of the neck.

26th.-Calomel had operated freely ; mind more calm and collected, but not perfectly rational. A general distress and restlessness pervaded the whole system. No arterial excitement or general re-action had yet taken place. Pulse varied from 90 to 120 . During the day, syniptoms of cerebral disturbance and organic disease increased. In the evening, at my request, my friends Drs. Parsons and Smith saw ber with me, in consultation. Similar measures were continued, with the addition of ammonia and other diffusible stimulants.

27 th.-She had no rest during the night; pulse diminished in force and frequency; mind more incoherent and comatose; secretions all scanty and vitiated. Wound examined, and found livid and flabby, and exhibiting no signs of reparaticn.

These symptons and others, indicating approaching dissolution, increased, in spite of all treatment, until the $29 \mathrm{~h}$, the sixth day after the operation, the patient died, apparently from inflammation of the brain. To my extreme regret, a post-mortem examination could not be obtained.

On examination of the morbid growth, the disease was found to consist of a tumor the size of a small orange, which conmenced in the centre of the optic nerve, between its exit from the foramen opticum, and its entrance into the globe of the eye.

As the tumor increased in size, the neuralema and nerrous filaments yielded, and became so expanded over the whole periphery of the tumor; as to form a complete tunic. On dividing this covering, the morbid structure was easily separated from it. Its color was nearly that of chocolate, and of the consistence of liver. Its organization was very imperfect, being easily broken down with the finger, and perneated in many parts by irregular sinuosities. Whether or not the idea is correct, it is impossible to determine, but 1 was impressed with the suggestion that this abnormal growth might have arisen from the organization of a small quantity of blood, which might have been extravasated in the substance of the nerre; occasioned by an early rupture of the arteria centralis retina.

This case is interesting in many respects; but particularly that the patient, after a complete and speedy removal of a tumor of the orhit, ap- 
parently in no way connected with the brain, should die so suddenly from inflam:nition of that organ. A post-mortem exanination would probably have reveded the fact that organic disease had already cornmitted fatal ravagres within the craniun.-Droceedings of the Ohio Med. Convention.

\section{CHRONIC CASE TREATED HOMGEOATHICALLY.}

To the Editor of the Boston Medical and Surgical Journal.

Sir,- - I would not trouble you or your readers with another article, were it not for further inquiries of our friend, Dr. Leonard, and the necessity of some remarks still further on our cases, arising from the conclusions which have been drawn from them. Hornœopathic cures have commonly (by those not acquainted with the subject) been attributed to imagination; but in our cases this will not do, and therefore "confidence" and "nature" come in for the credit. Let us look at this. In regard to the first case of ours, Drs. Clough and Leonard attribute the cure to the venesection and purging. Now they will observe that the patient had been sick some twelve hours when he was bled and purged; in some fifteen bours after, I was called to see him. His disease was now much more scverc than when the other physician was called. If the venesection had the effect, why should it allow the disease to become aggravated for fifteen hours, and then suddenly take effect? Had any allopathic practitioner been called at the same time, we are certain the patient would have been bled again, and other active antiphlogistic treatment adopted. In the second case (also inflammation of the boivels) Dr. C. says the "evacuations were favorable, puking, purging and sweating." Why don't he add, pain, tympanitis, pulse 112 , \&c. We were not before aware that sweating night not be a morbid phenomenon, a synupton we have observed so often in hectic, in typhus, in cholera, and in bilious enteritis. Puking and purging we have often considered morbid actions. Dr. C. thinks this case cured in "spite of the medicine;" while Dr. L. says " small doses of mercury are efficient as a curative." Dr. C. says, "These cases are valuable in one point; they show the profession how little reliance should be placed on inedicinal agents, and how much on the natiaral powers of the system." Here is the most fatal error into which the profession can fall. It arises, in the first place, from assuming that homœopathic treatment is inefficient, and consequently it must be nature which effects the cure. The assumption is false, and the conclusion therefore erroneous. We would just invite Dr. C. to compare the state of these cases with the pathogenetic and curative action of the drugs which were used, and see if there is any analogy. The reason "nature" did not start on our first prescription in the second case, was that the remedy was not appropriate, and we were to blame. Again, Dr. C. says "they were inspired by hope, which could not be induced by a different class of practitioners." How so? In the first case the patient had high confidence in his physician, and neither of them had ever before seen me; and the second was a perfect invincible in favor of 